\title{
A brief study on matrix converter for wind mill application
}

\author{
M. Devika \\ L. Pavithra \\ Christ the King Engineering College, Karamadai, Tamil Nadu 641104 \\ devikav66@gmail.com \\ Pavibhuvi01@gmail.com
}

\begin{abstract}
The wind energy is one of the low qualities because of change in direction and velocity of wind. So, the input power and the frequency will be varied which affects the operation of system. For a prescribed wind velocity, the mechanical power available from the wind turbine is function of shaft speed. The shaft speed is varying due to the change in the wind velocity; thereby change in frequency and voltage is developed at the output of the induction generator. Power electronics converters are used for stabilizing the varying parameters and to obtain a constant frequency of $50 \mathrm{~Hz}$. commonly used power electronic device is back-to-back converters or AC$D C$-AC converters which has many disadvantages like costly, bulky. Through matrix converter, the terminal voltage and frequency of the induction generator can be controlled in such a way that the wind turbine will be operating at a constant frequency of $50 \mathrm{Hertz}$.
\end{abstract}

Keywords: Wind Energy Conversion System, Brushless Doubly Fed Reluctance Generator

\section{INTRODUCTION}

Wind is one of the most copious available renewable sources of energy in nature. The wind energy can be tackled by wind energy conversion system (WECS), composed of a wind turbine, an electric generator, a power electronic converter and required control system. In wind turbines, mechanical power of the blades is transferred to the Turbine's rotor, either directly or by use of gear boxes; and the generated energy, in most cases, is transferred to the power distribution network. Therefore, the quality of produced power is in high value of importance. The quality of the power produced is overblown by the amplitude of generator's voltage. In this regard, several methods have been proposed to fix the varying frequency. One of these methods is the use of Back-to-Back Converters where the alternating voltage of the turbine is converted to constant voltage using converters and then by the use of an inverter, voltage proportional to the network voltage is produced. The other method used, is to sample the wind velocity and change the blades angle with respect to the variations of winds velocity. In this method the response is slow and time consuming and causes mechanical erosion of parts if used for a long period of time. Dissimilar controllers find the maximum power for given wind operation by employing an elaborate searching method. In another method, increasing inertial 
momentum of turbine's shaft is proposed to overcome rapid fluctuations of wind. In order to perform speed control of the turbine shaft to achieve maximum power, different control methods such as field-oriented control and constant V/f have been used. With the above analysed drawbacks, the MATRIX CONVERTER was implemented in wind applications as it stabilizes the frequency variations. Through matrix converter, the terminal voltage and frequency of the induction generator can be controlled, so the wind turbine will be operating at a frequency of $50 \mathrm{~Hz}$.

\section{WIND ENERGY CONVERSION SYSTEM}

A wind energy conversion system is composed of blades, an electric generator, a power electronic converter, and a control system. Changing the kinetic energy into electric power and injecting this electric power into the electrical load or the utility grid.

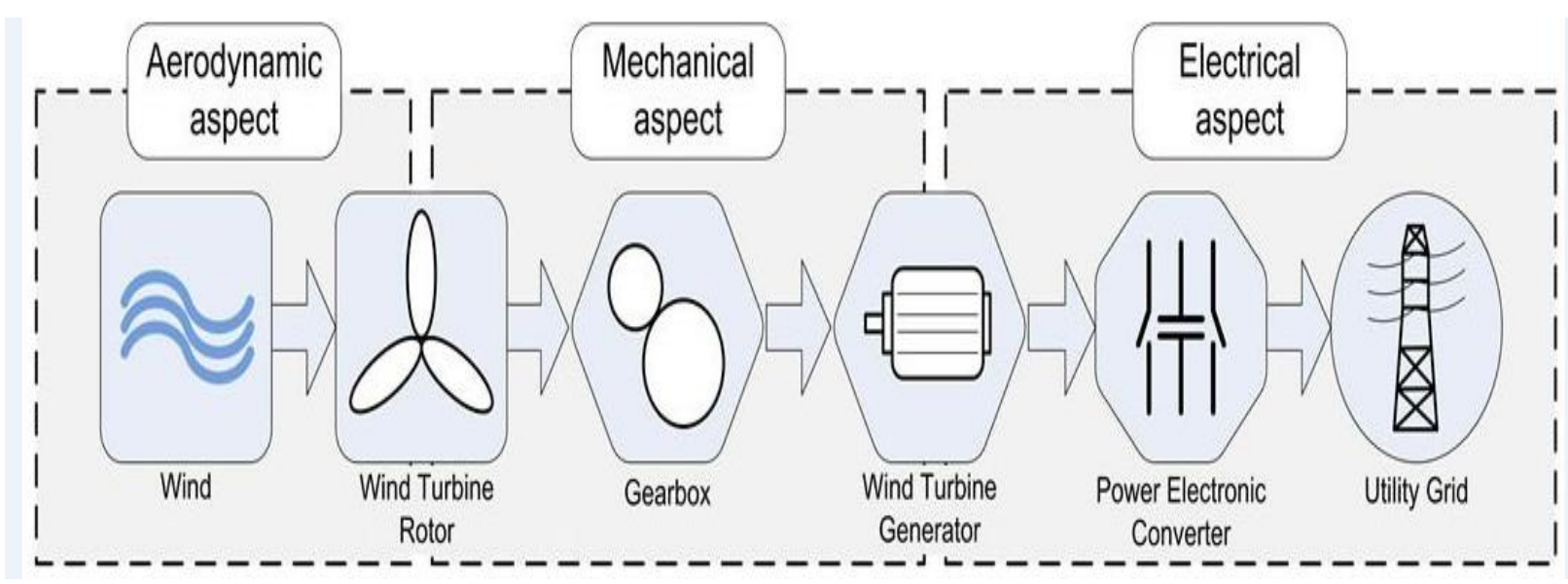

Figure 1.1. Block diagram of a WECS

Maximum power, $\operatorname{Pmax}=0.593\left(1 / 2 \rho \mathrm{AV}^{\wedge} 3\right)$

Total power in wind stream $=1 / 2 \rho \mathrm{AV}^{\wedge} 3$

Power coefficient is the ration of maximum output power to total power available in the wind,

$$
\eta_{\text {max }} \text { or } C_{p}=\frac{\rho_{\max }}{\rho_{\text {total }}}=0.539
$$

Where,

$\mathrm{P}$ is the power in $\mathrm{W}$,

$\rho$ is the air density in $\mathrm{g} / \mathrm{m}^{3}$,

$\mathrm{Cp}$ is a dimensionless factor called power coefficient,

A is the turbine rotor area in $m^{2}\left(A=\pi R^{2}\right)$,

where $\mathrm{R}$ is the rotor blade radius)

$\mathrm{V}$ is the wind speed in $\mathrm{m} / \mathrm{s}$. 


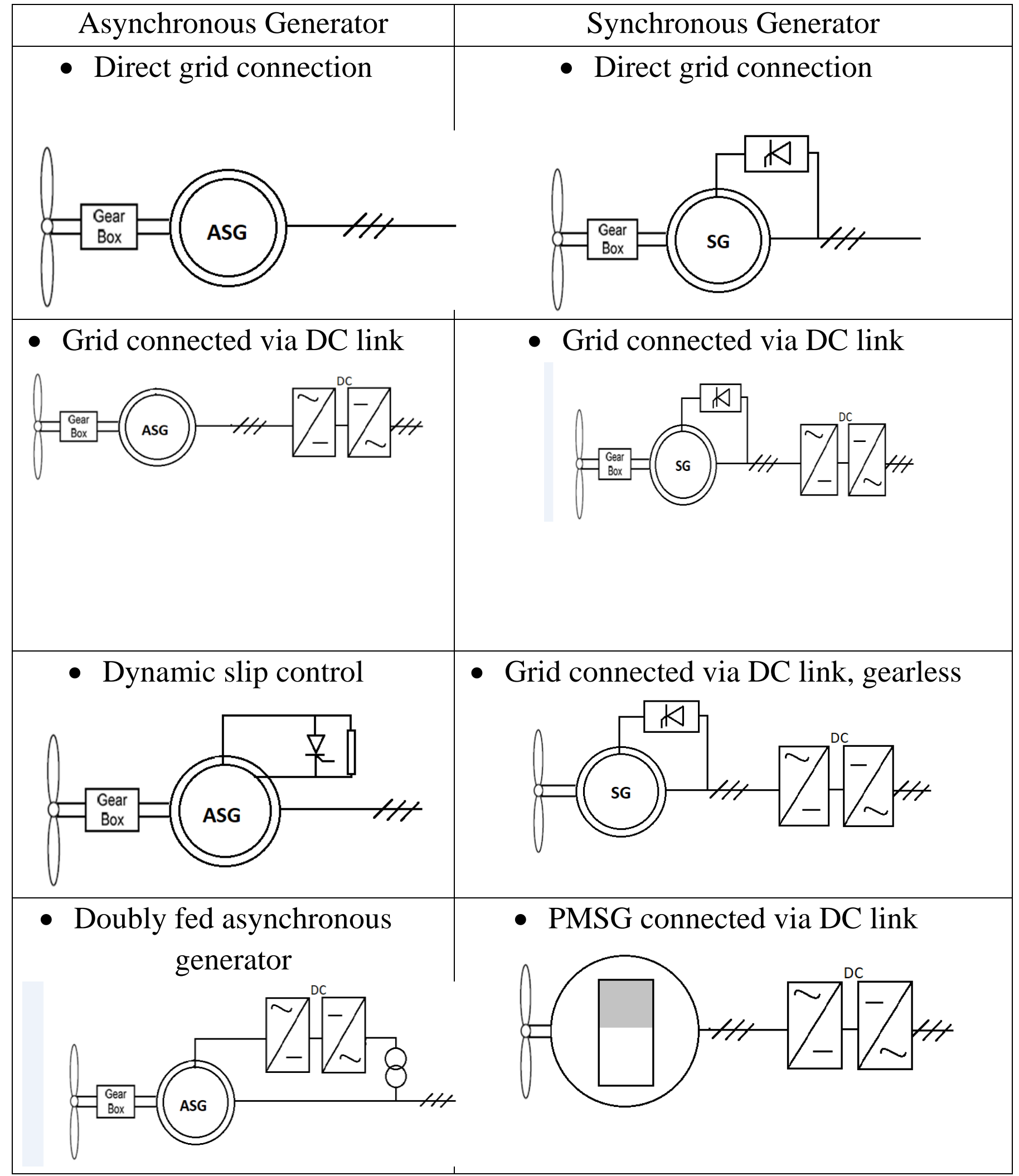

Figure 2.2. Different topologies of wind energy conversion systems 


\section{WIND TURBINE GENERATORS}

\subsection{Wind Turbine Generators in the Current Market}

WTGs can be classified into three types according to its operation speed and the size of the associated converters as below:

- FSWT (Fixed Speed Wind Turbine)

- VSWT (Variable Speed Wind Turbine) with:

- PSFC (partial scale frequency converter)

- FSFC (full scale frequency converter) FSWT including SCIG (Squirrel-Cage Induction Generator), led the market until 2003 when DFIG (Doubly Fed Induction Generator), which is the main concept of VSWT with PSFC, overtook and has been the leading WTG concept with $85 \%$ of the market share reported in. PMSG (Permanent Magnet Synchronous Generator) has been drawing increased attention and increasing its market share in the past several years due to the benefits of PMSG and disadvantages of WRSG .Since there is much literature available on these WTG concepts in the market such as, the following section will only address the two newer concepts of WTGs, which are BDFIG (Brushless Doubly Fed Induction Generator) and BDFRG (Brushless Doubly Fed Reluctance Generator), followed by the discussion with the comparison of them to the present concepts.

\subsection{Newer WTG concepts:}

\subsubsection{BDFIG (Brushless Doubly Fed IG)}

BDFIG is one of the most popular VSWT with PSFC types in the current research area due to its increased characteristics of DFIG, which is the most popular WTG type at the current market, along with its brushless aspect that DFIG do not possess. As shown in, BDFIG consists of two cascaded induction machines; one is for the generation and the other is for the control in order to eliminate the use of slip rings and brushes, which are the main drawback of DFIG. This brushless concept increases reliability, which is desirable in offshore application. Other advantages are reported including its capability with low operation speed. On the other side, BDFIG has complex aspects in its design, assembly and control, which are some of the main disadvantages of BDFIG.

\subsubsection{BDFRG (Brushless Doubly Fed Reluctance Generator)}

There is also another brushless and two-cascaded-stator approach of VSWT with PSFC type in the research area, which is BDFRG. The design is compared with BDFIG is its reluctance rotor, which is usually an iron rotor without copper windings, this has lower cost than wound rotor or PM. 


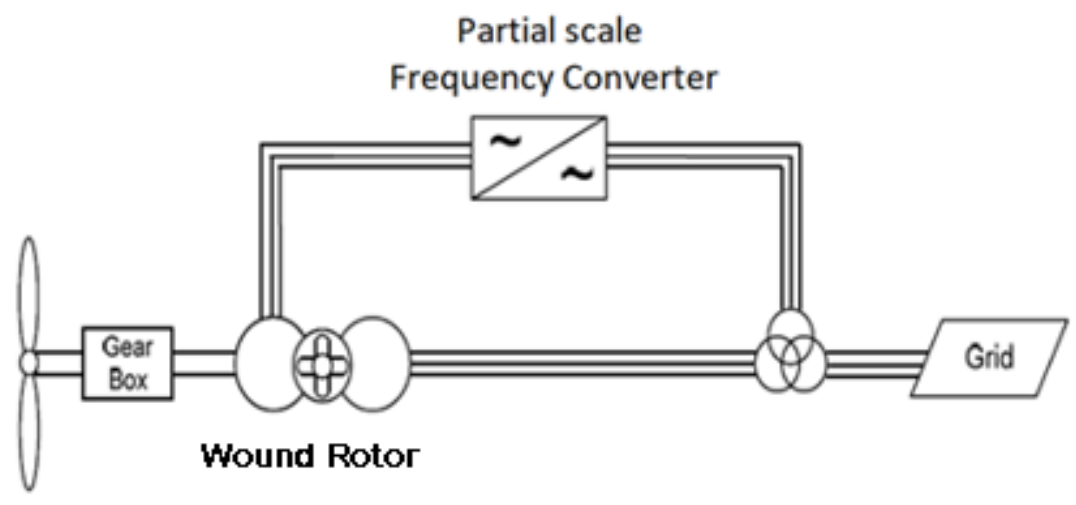

Figure 3.2. The conceptual diagram of BDFIG

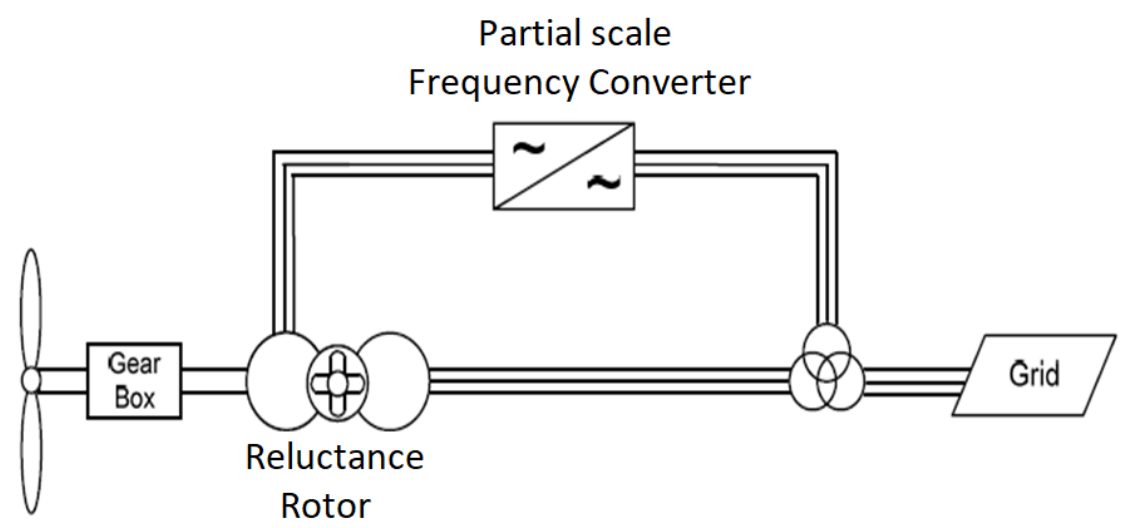

Figure 3.2. The conceptual diagram of BDFRG

This design offers some advantages on top of the advantage of BDFIG including higher efficiency, easier construction and control including power factor control capability as well as reduction in cost and increased reliability including its "fail-safe" operation mode due to the reluctance rotor. Due to its increased reliability, reluctance generators have also been of interest in aircraft industry where design challenges such as harsh environment operation and stringent reliability exist. On the other hand, some of the drawbacks for BDFRG exist such as complexity of rotor deign, its larger machine size due to a lower torque-volume ratio.

\section{MATRIX CONVERTER}

Matrix converter (MC) is a one-stage $\mathrm{AC} / \mathrm{AC}$ converter composed of an array of nine bidirectional semiconductor switches, connecting each phase of input to each phase of output. The foremost advantage of matrix converter is elimination of dc link filter. Zero switching loss devices can transfer input power to output power without any power loss. But practically it does not exist. 


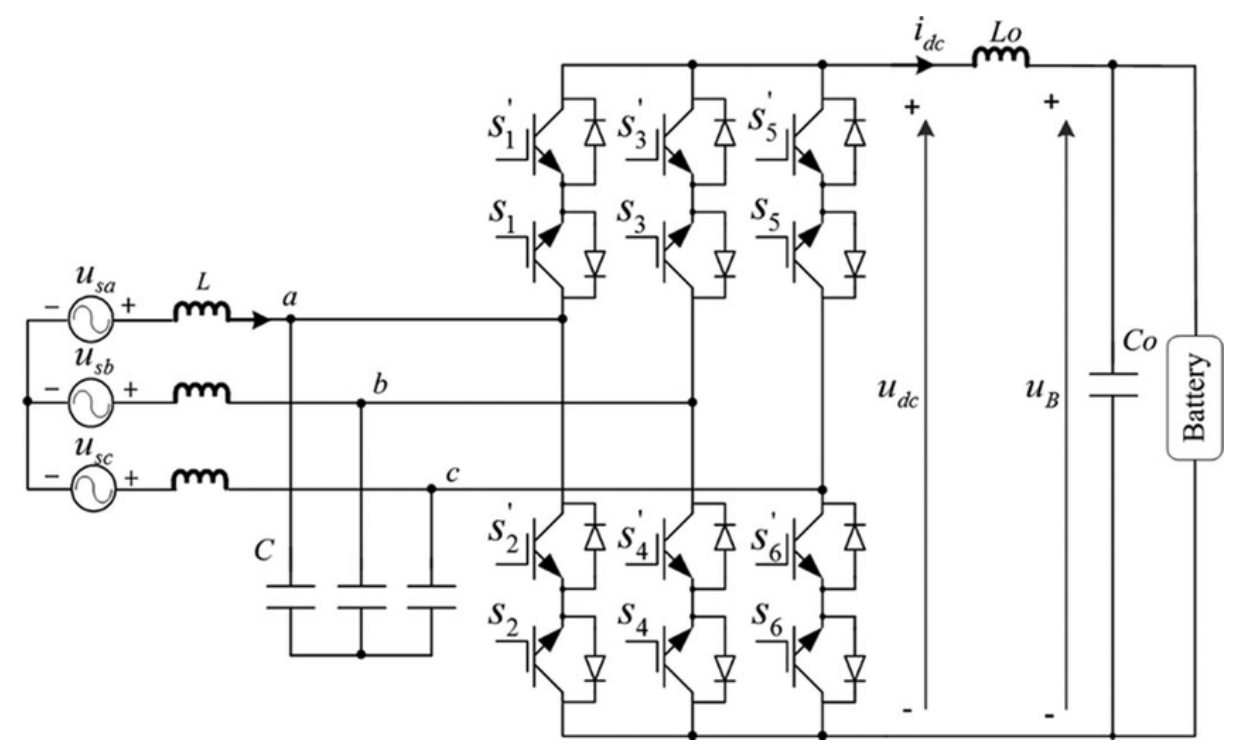

Figure 4.3. Matrix converter circuit topology

The switching frequency of the device decides the THD of the converter. Maximum power transfer to the load is decided by the control algorithm. Matrix converter has increased input output voltage transfer ratio limited to $87 \%$ for sinusoidal input and output waveforms, which can be improved. Further, matrix converter requires more semiconductor devices compared to conventional AC-AC indirect power frequency converter. Since monolithic bi-directional switches are available, they are used for switching purpose.

\subsubsection{Control Technology}

With the matrix converter, simultaneous control of the output voltage and input current is possible, but simultaneous and independent control is difficult to implement. The control method becomes complicated because of switching one bi-directional switch. The higher speed, the higher performance and lower cost of control devices in recent years, however, have made it possible to realize even complicated control with ease. In the conventional control method for a matrix converter, the pulse pattern for bi-directional switch is calculated The control method is unique for the matrix converter and is capable of outputting various pulse patterns. However, the pulse pattern is calculated directly, it is difficult to control the input current and the output voltage independently.

\subsubsection{Performance Parameters}

Since there is no energy storage components present between the input and output side of the matrix converter, the output voltage has to be produced directly from the input voltages. Each output voltage waveform is synthesized by sequential piecewise sampling of the input voltage waveforms. The sampling rate has to be higher than both input and output frequencies, and the duration of each sample is controlled so that the average value of the output waveform within each sample period tracks the desired output waveform. 


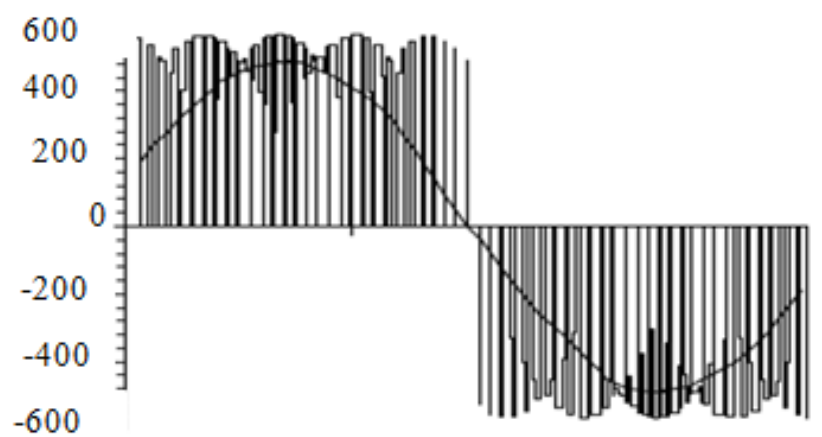

Figure 4.2. Output voltage of a matrix converter

The input currents are directly generated by the output currents, synthesized by sequential piecewise sampling of the output current waveforms. If the switching frequency of the matrix converter is set higher than the input and output frequency, the input currents drawn by the converter are sinusoidal. The input power factor is another attractive feature of matrix converter, which holds for most of the control algorithms. Despite this common capability, it is worth noting that a basic difference exists with respect to the load displacement angle dependency.

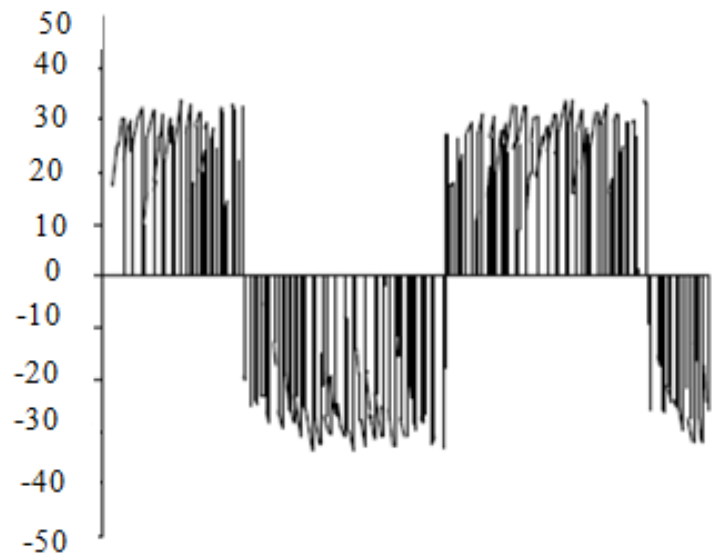

Figure 4.3. Input current of matrix converter

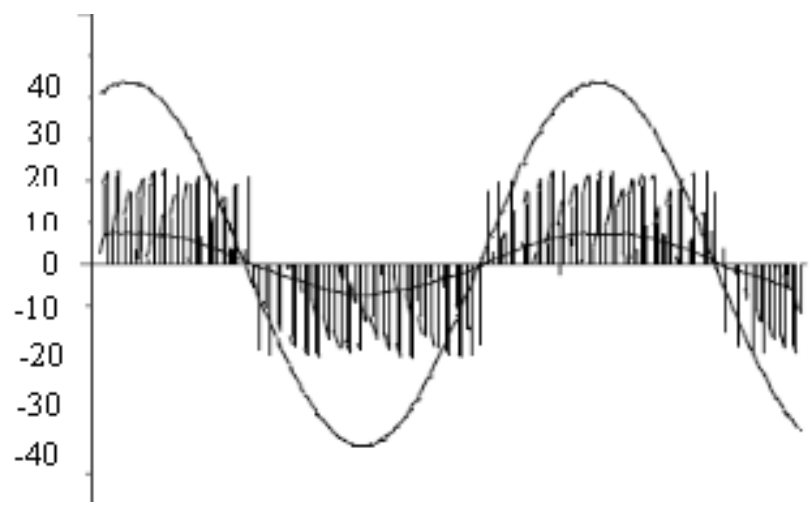

Figure 4.4. Input line-to-neutral voltage 
For example, the algorithm does not require the knowledge of the load displacement angle in order to fully control the input power factor. On the contrary, the algorithm requires the knowledge of the load displacement angle whenever the reference input power factor is different from unity. From an algorithm computational burden point of view this is a drawback, since it implies additional quite heavy calculations.

\subsection{COMMUTATION METHODS IN MATRIX CONVERTER}

\subsubsection{Dead Time Commutation}

Dead Time commutation method is used in inverter side. In matrix converter dead time commutation method cannot be used. It results in the open circuit at the load side. Then spike occurs across the switches. To avoid this snubber clamping devices are provided. This is a path to the load current during the dead time and hence the design of snubber circuit is difficult.

\subsubsection{Current Commutation based on Multiple Steps}

Current Commutation uses bidirectional switches. It is reliable in current commutation and obeys the basic rules. It can be able to control the direction of the current. This strategy is essential in case of controlled current flow. Current Commutation technique relies on knowledge of the output current direction. The current direction is difficult to determine and allow current levels in high power drives. To avoid this technique of using the voltage across the bi-directional switch is used to determine the current direction has been developed. This technique provides reliable current commutation using an intelligent gate drive circuit which controls the firing of the IGBTs and detects the direction of current flow within the bidirectional switch cell. The current direction information calculated by the active gate drive is passed to all the other gate drivers on the same output leg. In this way all the gate drivers contribute to operate a safe commutation.

\begin{tabular}{|c|c|c|c|c|c|c|c|c|c|}
\hline $\mathrm{T} 1 \mathrm{~S}$ & $\mathrm{~S}_{\mathrm{Aa}}$ & $\mathrm{S}_{\mathrm{Ab}}$ & $\mathrm{S}_{\mathrm{Ac}}$ & $\mathrm{S}_{\mathrm{Ba}}$ & $\mathrm{S}_{\mathrm{Bb}}$ & $\mathrm{S}_{\mathrm{Bc}}$ & $\mathrm{S}_{\mathrm{Ca}}$ & $\mathrm{S}_{\mathrm{Cb}}$ & $\mathrm{S}_{\mathrm{Cc}}$ \\
\hline $\mathrm{T} 1$ & 1 & 1 & 1 & 0 & 0 & 0 & 0 & 0 & 0 \\
\hline $\mathrm{T} 2$ & 1 & 1 & 0 & 0 & 0 & 1 & 0 & 0 & 0 \\
\hline $\mathrm{T} 3$ & 0 & 0 & 0 & 1 & 1 & 1 & 0 & 0 & 0 \\
\hline $\mathrm{T} 4$ & 0 & 0 & 0 & 1 & 1 & 0 & 0 & 0 & 1 \\
\hline $\mathrm{T} 5$ & 0 & 0 & 0 & 0 & 0 & 0 & 1 & 1 & 1 \\
\hline $\mathrm{T} 6$ & 1 & 1 & 1 & 0 & 0 & 0 & 0 & 0 & 0 \\
\hline $\mathrm{T} 7$ & 1 & 1 & 0 & 0 & 0 & 1 & 0 & 0 & 0 \\
\hline $\mathrm{T} 8$ & 0 & 0 & 0 & 1 & 1 & 1 & 0 & 0 & 0 \\
\hline $\mathrm{T} 9$ & 0 & 0 & 0 & 1 & 1 & 0 & 0 & 0 & 1 \\
\hline $\mathrm{T} 10$ & 0 & 0 & 0 & 0 & 0 & 0 & 1 & 1 & 1 \\
\hline $\mathrm{T} 11$ & 1 & 1 & 1 & 0 & 0 & 0 & 0 & 0 & 0 \\
\hline $\mathrm{T} 12$ & 1 & 1 & 0 & 0 & 0 & 1 & 0 & 0 & 0 \\
\hline
\end{tabular}




\begin{tabular}{|c|c|c|c|c|c|c|c|c|c|}
\hline T13 & 1 & 0 & 0 & 0 & 1 & 1 & 0 & 0 & 0 \\
\hline T14 & 0 & 0 & 0 & 1 & 1 & 1 & 0 & 0 & 0 \\
\hline T15 & 0 & 0 & 0 & 1 & 1 & 0 & 0 & 0 & 1 \\
\hline T16 & 0 & 0 & 0 & 1 & 0 & 0 & 0 & 1 & 1 \\
\hline T17 & 0 & 0 & 0 & 0 & 0 & 0 & 1 & 1 & 1 \\
\hline T18 & 1 & 1 & 1 & 0 & 0 & 0 & 0 & 0 & 0 \\
\hline T19 & 1 & 1 & 0 & 0 & 0 & 1 & 0 & 0 & 0 \\
\hline T20 & 1 & 0 & 0 & 0 & 1 & 1 & 0 & 0 & 0 \\
\hline T21 & 0 & 0 & 0 & 1 & 1 & 1 & 0 & 0 & 0 \\
\hline T22 & 0 & 0 & 0 & 1 & 1 & 0 & 0 & 0 & 1 \\
\hline T23 & 0 & 0 & 0 & 1 & 0 & 0 & 0 & 1 & 1 \\
\hline T24 & 0 & 0 & 0 & 0 & 0 & 0 & 1 & 1 & 1 \\
\hline
\end{tabular}

Table 1. 1 Switching States of Mc

\subsection{Simulation of Matrix Converter}

The matrix converter was simulated using MATLAB/SIMULINK. Its model and output voltage, current was illustrated below

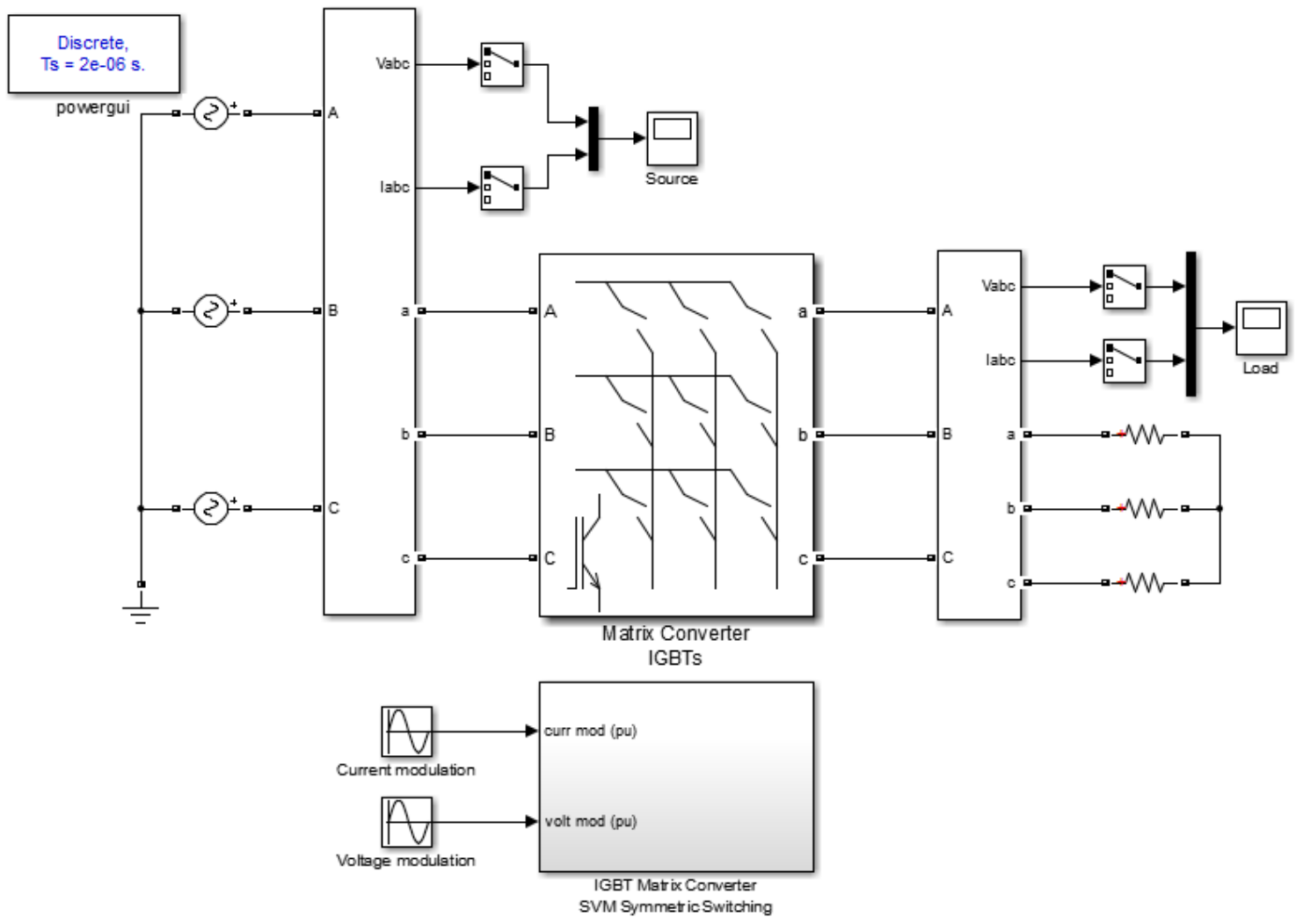

Figure 4.5. Simulation of Matrix Converter 


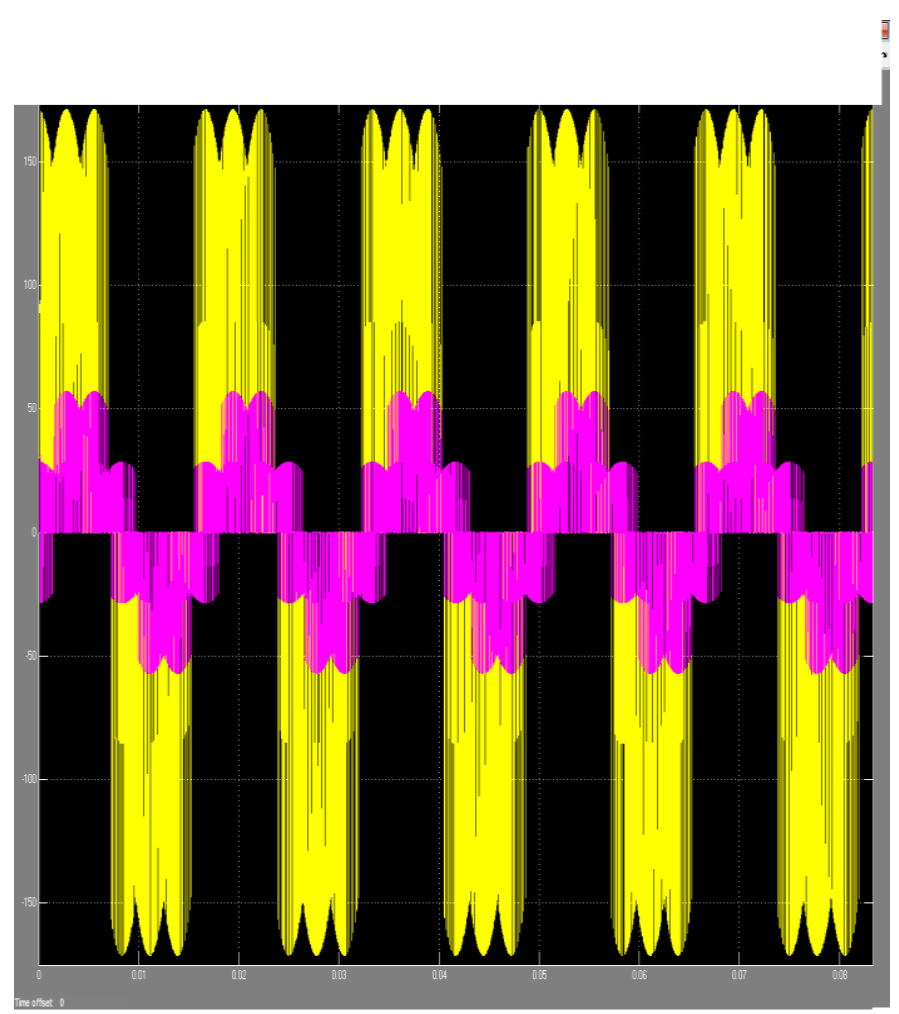

\section{Output Voltage}

\section{Output Current}

Figure 4.6. Output Voltage and Current of Matrix Converter

\subsection{Advantages of Matrix Converter}

The main advantages of a matrix converter are:

$\checkmark$ Sinusoidal input and output waves with minimum harmonics.

$\checkmark$ Input power can be fully controlled.

$\checkmark$ Minimum energy storage requirements.

$\checkmark$ Compact design.

$\checkmark$ Adjustable (including unity) power factor.

$\checkmark$ Bidirectional power flow.

$\checkmark$ High quality waveform.

$\checkmark$ More stability and fewer fluctuations.

\subsection{Disadvantages of Matrix Converter}

The main drawbacks of a matrix converter are:

$\checkmark$ Higher complexity in modulation and analysis effort.

$\checkmark$ Requires more semiconductor devices.

$\checkmark$ Sensitive to disturbances of the input voltage. 


\section{Issues on Grid-Connection}

\subsection{The Utility Grid and WECS}

Some grid disturbances such as voltage dips often occur on utility side. In the past, gridconnected wind turbines needed to be disconnected from the grid when such disturbances happened in order to protect themselves from damages. However, as the penetration level of wind energy has been increasing the role of WECS on the grid has been transforming from minor power source to main power supply stations such as coal-fired power stations along with the new grid codes. Fault Ride Through (FRT) capability under voltage dip is one of the main focus of the new grid codes. Another focus of the new grid code is the requirement for wind turbines to support the power quality control on the grid such as voltage/frequency stability control, active/reactive power regulation, harmonics/interharmonics emission and flicker emission and so forth. International Electro technical Commission (IEC) has also released standards on power quality for grid connected wind turbines, which are IEC 61400-21 in 2001 and its second edition in 2008. In The following section will discuss three grid-connection issues that are most frequently reported and investigated in wind energy field, which are voltage dip, harmonic emission and flicker.

\subsection{The Three Main Issues in Grid-Connected WECS}

\subsubsection{Voltage Dip}

Voltage dip, also referred as voltage sag, is a phenomenon that the voltage of the grid drops below the normal rms level (down to 0.1-0.9 p.u.) for a short duration (typically $0.5-30$ cycles) .It is a critical issue for wind turbines because the voltage dip can initiate abnormal behaviors in the generator and PEC, which can result in permanent damages [83]. Therefore it is regarded as a significant technical challenge for wind turbine manufacturers [81]. Under the new grid codes, wind turbines are expected to have reasonable FRT capability, which is to support the grid under the voltage dip as well as to protect them from being damaged. Wind turbine must stay connected until the state (i.e. voltage-time) is placed below the solid line in the figure in order to support the grid.

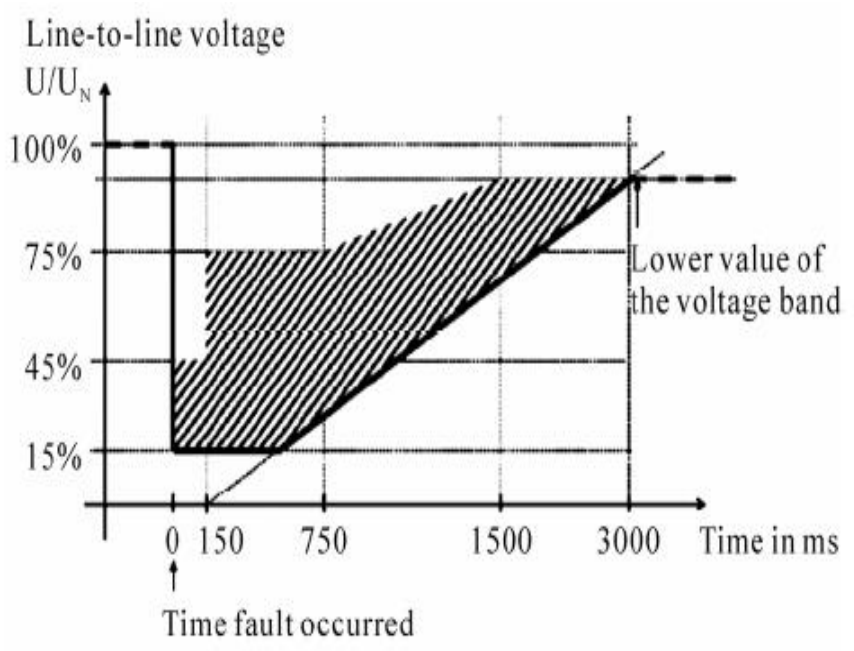

Figure 5.1. The FRT capability curve 


\subsubsection{Harmonic Emission}

Harmonic emission is another crucial issue for grid connected wind turbines because it may result in voltage distortion and torque pulsations, which consequently cause overheating in the generator and other problems. Although wind turbines emit low-order harmonics, selfcommutated converters are used in modern VSWTs which can filter out these low-order harmonics. But self-commutated converters introduce high-order harmonics. In addition, inter harmonics, which is non-integer harmonics, is another type of harmonic emission by WTCS's. Wind turbine power quality standard IEC 61400-21 $2^{\text {nd }}$ edition released in 2008, along with harmonic measurement standard IEC 61000-4-7, provides the requirements for on current harmonics, current interharmonics and higher current components to be measured and reported in modern WECS's.

\subsubsection{Flicker}

In wind turbine Flicker is another issue. It is defined as a measure of annoyance of flickering light bulbs on human, caused by active and reactive power fluctuation. The standard IEC 61400-21 requires flicker to be monitored in two operation modes; continuous operation and switching operation. It is reported that flicker is relatively less critical issue in VSWT; however, it needs to be improved for higher power quality.

\section{PROPOSED MODEL OF MC WITH DFIG}

Double-fed induction machines can be operated as a generator and motor in sub-synchronous and super-synchronous speeds, giving four possible operating modes. But the major drawback of DFIG is it consists of slip rings and brushes which decreases the overall efficiency. To overcome this, the proposed model is designed with brushless doubly fed induction generator which increases the efficiency and also can be used in off-shore wind applications.

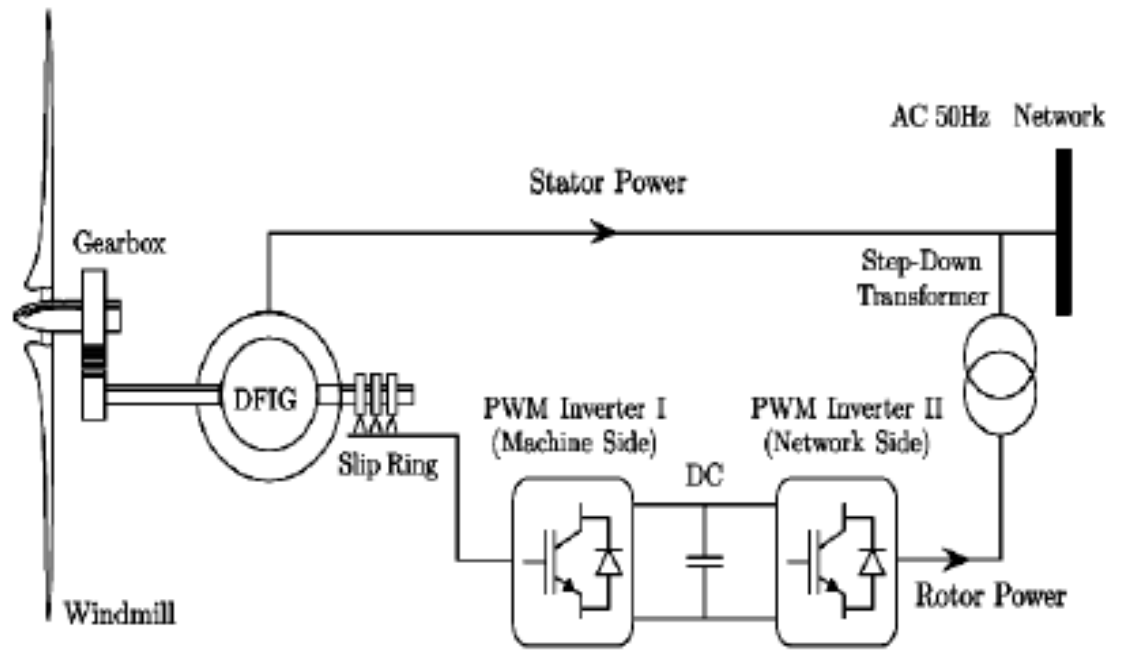

Figure 6.1. Conventional DFIG

The proposed model uses a brushless doubly fed induction generator as it operates more conveniently in variable speed with partial scale. BDFIG consists of two cascaded induction machines; one is for the generation and the other is for the control in order to eliminate the use 
of slip rings and brushes. The proposed topology is used for variable speed wind energy applications. The design of the control loops is simplified considering that the power spectrum density of a typical wind profile which has the available energy available in the low frequency region. No brushes are required for the connection of both rotors in a machine with two stators and one only rotor. It operates both in sub synchronous and super synchronous region.

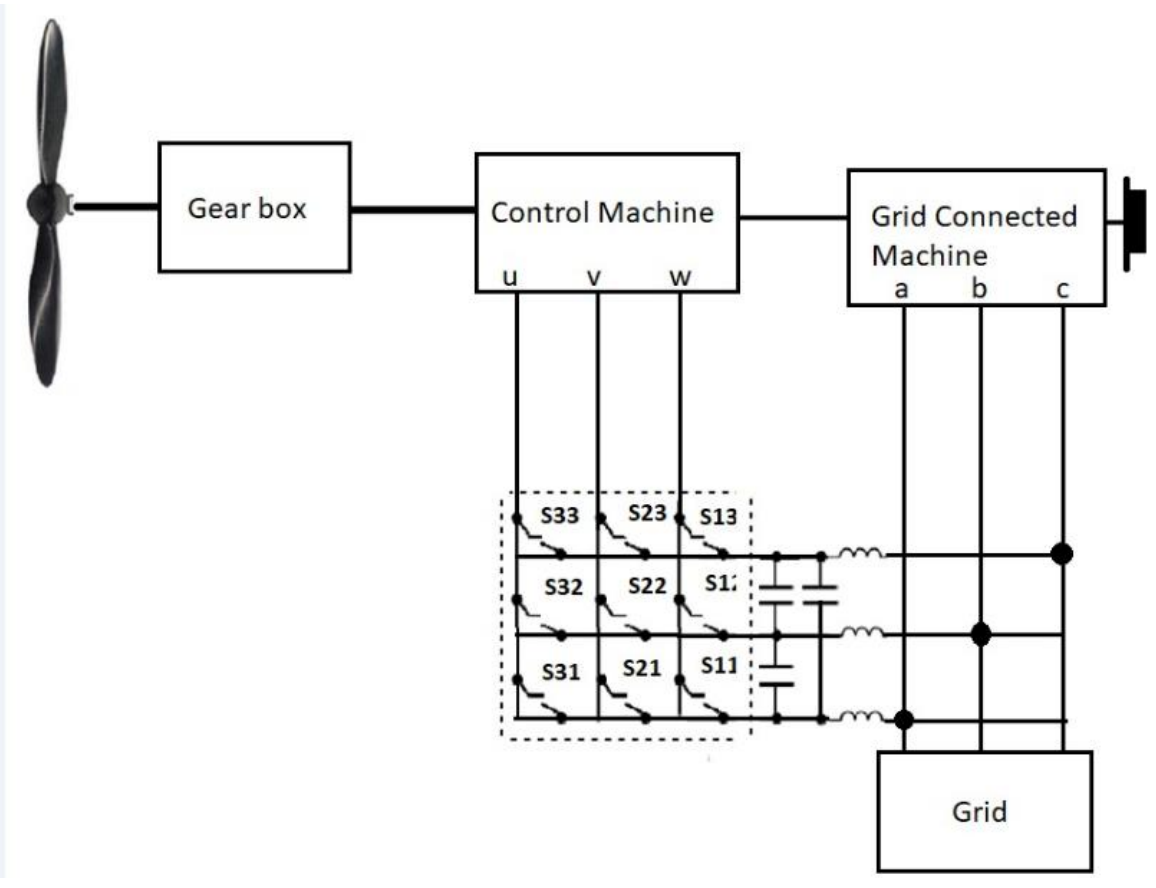

Fig 6.2 Proposed model of BDFIG

\section{CONCLUSIONS}

The paper mainly focus on the use of matrix converter in wind mill applications because its efficiency decreases with increasing frequency than a back-to-back converter. In high frequency applications, this may be an argument to use a matrix converter. One of the key findings of this study is that the newer concepts, BDFIG and BDFRG have great potential to come into the WECS market in the current and future wind energy market due to their attractive characteristics in line with the current trends of the wind energy market. Hence, there need to be more researches on them with grid connection issues.

\section{REFERENCES}

[1].Lopez, S., "Matrix Converter for frequency changing power supply applications", Ph.D. dissertation submitted to U. of Nottingham, unpublished, 2008.

[2]. S. Masoud Barakati -A thesis.

[3]. Design and Simulation of Matrix Converter for Wind Mill Applications, International Journal of Advanced Trends in Computer Science and Engineering.

[4].Wind Energy Conversion System from Electrical Perspective -A Survey, Smart Grid and Renewable Energy, 2010. 
[5]. L. Ran, J. R. Bumby, and P. J. Tavner, "Use of turbine inertia for power smoothing of wind turbines with a DFIG, " Proc. 11st IEEE International Conference on Power Quality, pp. 106-111, 2004.

[6]. Performance analysis of wind turbine-driven permanent magnet generator with matrix converter Ramasamy, A. Nirmal Kumar, Turk J Elec Eng \& Comp Sci, Vol.20, No.3, 2012. [7]. P. Bauer, et al., "Evaluation of Electrical Systems for Offshore Windfarms," Industry Applications Conference, Vol. 3, 2000, pp. 1416-1423.

[8] S. Shiyi, et al., "Dynamic Analysis of the Brushless Doubly- Fed Induction Generator during Symmetrical Three- Phase Voltage Dips," International Conference on Power Electronics and Drive Systems, Taipei, 2009, pp. 464-469.

[9] P. Camocardi, et al., "Autonomous BDFIG-Wind Generatorwith Torque and Pitch Control for Maximum Efficiency in aWater Pumping System," International Journal of Hydrogen Energy, Vol. 35, No. 11, 2010, pp. 5778-5785 